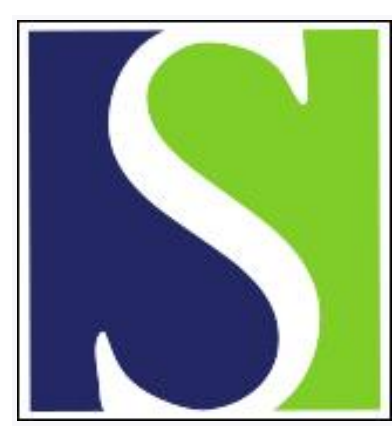

Scand J Work Environ Health 2000;26(2):153-160

https://doi.org/10.5271/sjweh.525

Issue date: Apr 2000

Modification of serum proteins in guinea pigs immunized and challenged with toluene diisocyanate

by De Marzo N, Jovine L, Rizzotti P, Ca ssetti P, Boschetto P, Miotto D, Saetta M, Maestrelli P, Mapp CE

Key terms: adduct; inflammation; isocyanates; protein

This article in PubMed: www.ncbi.nlm.nih.gov/pubmed/10817381

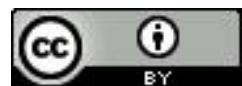




\title{
Modification of serum proteins in guinea pigs immunized and challenged with toluene diisocyanate
}

\author{
by Nicoletta De Marzo, MD, ${ }^{1}$ Laura Jovine, PhD, ${ }^{1}$ Paolo Rizzotti, MD, ${ }^{3}$ Paola Cassetti, PhD, ${ }^{3}$ \\ Piera Boschetto, MD, ${ }^{2}$ Deborah Miotto, PhD, ${ }^{1}$ Marina Saetta, MD, ${ }^{1}$ Piero Maestrelli, MD, ${ }^{1}$ \\ Cristina E Mapp MD'
}

\begin{abstract}
De Marzo N, Jovine L, Rizzotti P, Cassetti P, Boschetto P, Miotto D, Saetta M, Maestrelli P, Mapp CE, Modification of serum proteins in guinea pigs immunized and challenged with toluene diisocyanate. Scand $J$ Work Environ Health 2000;26(2):153-160.
\end{abstract}

Objectives Guinea pigs were used to determine whether immunization and challenge by toluene diisocyanate (TDI) induce changes in the serum protein concentrations of the "acute-phase response" and whether TDI can form adducts with serum proteins.

Methods Guinea pigs were immunized by weekly intradermal injections of TDI and challenged with TDI 7 days after the $3 \mathrm{rd}$ injection. The animals were killed 6 hours after the challenge, and serum was analyzed for protein characterization by gel electrophoresis and for specific antibodies to TDI by enzyme-linked immunosorbent assay (ELISA) and Western blotting.

Results The total serum protein concentration of the immunized TDI-challenged guinea pigs increased in comparison with that of nonimmunized animals [75 (SE 0.7) versus 47.4 (SE 2.3) $\mathrm{mg} / \mathrm{ml}$; ]. Albumin and alpha and alpha ${ }_{2}$ globulins increased significantly [respectively: 65.8 (SE 0.2 )\%, 2.1 (SE 0.1 )\% and 7.2 (SE 0.1 )\% versus

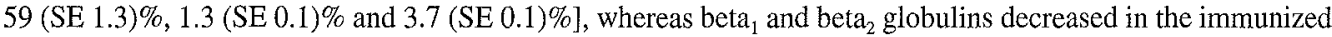
TDI-challenged guinea pigs [7.8 (SE 0.2)\% and 0.8 (SE 0.2)\% versus 15.8 (SE 0.7)\% and 4.8 (SE 0.2)\%]. The gamma globulin concentrations did not change significantly. In the immunized TDI-challenged animals, albumin was modified by TDI and ran faster on agarose gel electrophoresis than did albumin from nonimmunized guinea pigs. In the ELISA, only immunized animals had high titers of TDI-specific antibodies ( $\operatorname{IgG}$ and $\operatorname{IgG}_{1}$ ); by blotting, the antibodies reacted against TDI, the TDI-BSA-conjugate and several TDI-conjugated guinea pig serum proteins, but they did not react against any native or denaturated serum protein when unconjugated with TDI.

Conclusions These findings indicate that, in guinea pigs, immunization and challenge with TDI induces changes in serum proteins of the "acute phase response" and TDI is adducted to serum proteins with different molecular weights (eg, albumin).

Key terms adducts, inflammation, isocyanates, proteins.

Toluene diisocyanate (TDI), a potent low-molecularweight compound, is extensively used in the manufacture of polyurethane plastics and coatings (1). The high degree of chemical reactivity of isocyanates that contributes to their industrial value may play a role in their toxicity. In fact, TDI is a highly reactive compound that, by means of the reactive functional group - $\mathrm{NCO}$-, modifies mainly the sulfydryl and the hydroxyl groups in proteins (2-4). Since TDI is a small molecule, it is likely that TDI by itself is not antigenic, but it can act as a hapten and induce cellular immune responses (5). Challenge with airborne isocyanates causes a range of respiratory disorders in humans (6) and hypersensitivity reactions in animals (7); moreover, aromatic diisocyanates may give, as hydrolysis products, aromatic amines that are potential human carcinogens (8). It is still unknown what happens in vivo after the inhalation of toluene diisocyanate and which reactions occur between TDI and components of the body, such as proteins and water. The characteristics of asthma induced by isocyanates suggest an immunologic mechanism, but only a small percentage of asthmatics has been shown to have specific immunoglobulin (Ig) $\mathrm{E}$ antibodies (9). However, specific IgG antibodies have been found in subjects with isocyanate-induced

1 Department of Environmental Medicine and Public Health, University of Padova, Padova, Italy.

2 Institute of Occupational Medicine, University of Ferrara, Ferrara, Italy.

3 Clinical Chemistry, Padova, Italy.

Reprint requests to: Dr Cristina E Mapp, Dipartimento di Medicine Ambientale e Sanitá Pubblica, Via Giustiniani 2, I-35128 Padova, Italy. [E-mail: mapp@ux1.unipd.it] 
asthma (10). In addition the role of cellular inflammation in TDI-induced asthma has been demonstrated (11). In sensitized subjects, exposure to TDI has caused a recruitment and activation of inflammatory cells in the airways, increased the circulating CD8 + T-cells and eosinophils $48-72$ hours after exposure to TDI (12), and increased eosinophils in the sputum of subjects with TDIinduced asthma (13). Cytotoxic cells seem to play a role in TDI-induced asthma (14). These interacting cells, when activated, may release a whole variety of inflammatory mediators, including cytokines, mainly of the family of interleukin 1 (IL-1), interleukin 6 (IL-6), and tumor necrosis factor (TNF). It is known that these cytokines elicit the set of reactions known as "acute phase response", characterized by an increased liver synthesis of plasma proteins, referred to collectively as "acute phase proteins" (15). Very few studies have been conducted to evaluate the effect of the cascade of mediators on the liver synthesis of serum proteins.

Previously, we developed an animal model of TDIinduced asthma in guinea pigs, and we found an inflammatory cellular response in both the central and peripheral airways of immunized animals challenged by TDI, vith an increase of T-lymphocytes, mast cells, and eosinophils in the submucosa of the central airways (16). We also found an inflammatory response in peripheral blood that was characterized by an increase in metachromatic cells 24 hours after the TDI-challenge and a late increase in eosinophils 48 hours after the challenge.

In this study, we used guinea pigs to investigate whether immunization and challenge with TDI could induce an inflammatory response 6 hours after challenge, detectable by changes in the concentration of serum proteins, and a specific antibody response. Then, we characterized the binding of TDI to serum proteins by means of the antibodies obtained against TDI.

\section{Materials and methods}

\section{Immunization and challenge by toluene dissocyanate}

Male Dunkin Hartley guinea-pigs (Rodentia Laboratories, Torre Pallavicina, Italy), weight 300 to 350 grams, were used. They received 3 weekly intradermal injections of $50 \mu \mathrm{l}$ of $100 \%$ TDI $(2,4$ and 2,6 isomers, ratio $80: 20)$ or saline into each of 2 dorsal sites (16). The injection of $100 \mu \mathrm{l}$ of TDI was selected because this dose was able to induce both antibody production (17) and pulmonary sensitization in guinea pigs (16). Seven days after the 3rd injection of TDI, 5 animals of the group of immunized $(\mathrm{N}=10)$ and 5 of the group of nonimmunized animals $(\mathrm{N}=10)$ were challenged with TDI in a glass chamber $(30$ 1). The challenge was done as previously described (16). All the immunized guinea pigs showed local irritation at the sites of the 2nd and 3rd injection of TDI. All the animals survived to immunization and were challenged with TDI. They were killed 6 hours after the end of the TDIchallenge by an intraperitoneal injection of pentobarbital sodium $(100 \mathrm{mg} / \mathrm{kg})$.

\section{Preparation of serum, serum protein electrophoresis and antibody titer}

Blood samples were collected from the jugular vein immediately after the administration of the lethal dose of pentobarbital sodium. Serum was collected to measure the total amount of proteins, to characterize them, and to measure the titer of TDI-specific antibodies. After 1 hour at $37^{\circ} \mathrm{C}$, blood was centrifuged for 20 minutes at 7000 revolutions/minute and about $1 \mathrm{ml}$ of serum was obtained from all the specimens.

The total protein concentrations were measured by the method of Lowry et al (18). To characterize the serum proteins, electrophoresis was performed on agarose hydragel 30b1-b2 SEBIA®, running on a Beckman Paragon Electrophoresis System, and on cellulose acetate membranes, running on an automatized Olympus 620 System. Serum proteins were separated into albumin and alpha $_{1}$, alpha $_{2}$, beta, , beta $a_{2}$ and gamma globulins. The total serum protein concentrations were expressed in milligrams per milliliter, and the different fractions were expressed as the percentage of the total amount.

Total IgG and TDI-specific $\mathrm{IgG}_{1}$ antibodies were measured in the serum samples by enzyme-linked immunosorbent assay (ELISA). The ELISA titer was the highest serum dilution, yielding an absorbance value that was twice as high as that of the control serum and at least 0.1 absorbance units.

\section{Sodium dodecyl sulfate-polyacrylamide gel electrophoresis and Western blot}

Sera were mixed in a 1:1 ratio (volume/volume) with Laemmli's sample buffer solution, boiled for 5 minutes, and loaded in sodium dodecyl sulfate-polyacrylamide gel electrophoresis (SDS-PAGE), using 10\% acrylamide gel, with a ratio of acrylamide to $\mathrm{N}, \mathrm{N}$-methylenbisacrylamide of 30:0.8, according to a slightly modified method of Laemmli (19). Molecular weight markers (Sigma, Milan, Italy) were concurrently loaded in gel electrophoresis, and the gels were stained with Coomassie Blue. The protein concentrations in the samples were measured by the method of Lowry et al (18). Proteins were transferred from the gels to nitrocellulose membranes by electroblotting as described by Towbin et al (20). After the transfer, the blots were cut into strips and incubated with nonfat milk $(10 \%)$ in buffer Tris- $\mathrm{HCl}$ [composition in millimoles: 50 tris(hydroxymethyl)aminomethane-hydrochloric acid (Tris- $\mathrm{HCl}), 2$ calcium chloride $\left(\mathrm{CaCl}_{2}\right)$, and 85 sodium chloride $(\mathrm{NaCl}) \mathrm{pH} 8.0)$ ] for 1 hour at room temperature. Then, strips were incubated with immune 
serum anti-TDI $(0.42 \mathrm{mg} / \mathrm{ml})$ or with normal serum in nonfat milk (10\%) in buffer Tris- $\mathrm{HCl}$ for 2 hours at room temperature. After being washed for 20 minutes with $0.1 \%$ Tween-20 Tris- $\mathrm{HCl}$ and 20 minutes with $10 \%$ nonfat milk Tris- $\mathrm{HCl}$, the strips were incubated with a 1:1000 dilution of peroxidase-conjugated rabbit antiguinea pig immunoglobulins (Dako, Italy). As a control, strips were incubated without immune serum anti-TDI, but only with antiguinea pig immunoglobulins. After being washed, immunoreactive proteins were visualized by incubating the strips with $100 \mathrm{mM}$ Tris- $\mathrm{HCl}$ and $10 \mathrm{mM}$ imidazol (pH 7.6), $10 \mu \mathrm{l}$ of hydrogen peroxide $\left(\mathrm{H}_{2} \mathrm{O}_{2}\right)$, and $5 \mathrm{mg}$ of diaminobenzidin tetrahydrochloride dissolved in $1 \mathrm{ml}$ of methanol. When the bands were of the desired intensity, the strips were washed briefly in water.

\section{Toluene diisocyanate conjugates}

From the stock solution of TDI $\left(2 \times 10^{-3}-2 \times 10^{-5} \mathrm{M}\right)$ dissolved in dimethylsulfoxide (DMSO), $100 \mu$ was mixed with bovine serum albumin (BSA, $1 \mathrm{mg} / \mathrm{ml}$ ) or guinea pig serum for 1 hour at room temperature; then $50 \mu \mathrm{l}$ of the conjugates TDI-BSA and TDI-guinea pig serum were loaded in SDS-PAGE and tested on Western blotting with antibodies against TDI as previously described.

\section{Dot blot}

TDI $(50 \mu \mathrm{l})$ alone or conjugated with BSA $(250 \mu \mathrm{g}$ of BSA dissolved in $1 \mathrm{ml}$ of distilled water mixed with DMSO and incubated with TDI 15 minutes at room temperature, being mixed from time to time) were absorbed in native conditions on strips of nitrocellulose and then incubated with primary and secondary antibody, as described for Western blotting.

\section{Statistical analysis}

Values were expressed as means \pm the standard errors or as geometric means (GM) and geometric standard errors of the means (GSEM) when appropriate. Schaffe' test for multiple ranges was used to assess respectively the significance of differences in the total protein concentrations and the protein fractions between the nonimmunized and immunized animals and between the immunized TDIchallenged and immunized unchallenged animals. Probability values of $<0.05$ were accepted as significant.

\section{Results}

\section{Total amount of proteins and serum protein electrophoresis}

In the immunized guinea pigs challenged with TDI, the concentration of total serum proteins was significantly increased as compared with that of both the nonimmunized and immunized unchallenged animals [75.0 (SE
$0.7), 47.4$ (SE 2.3) and $53.6(\mathrm{SE} 1.0) \mathrm{mg} / \mathrm{ml}$, respective$1 y, \mathrm{P}<0.05]$. For the immunized TDI-challenged guinea pigs, there was a significant increase in the percentage of albumin and alpha ${ }_{1}$ and alpha $_{2}$ globulins and a significant decrease in the beta $a_{1}$ and beta $a_{2}$ globulins as
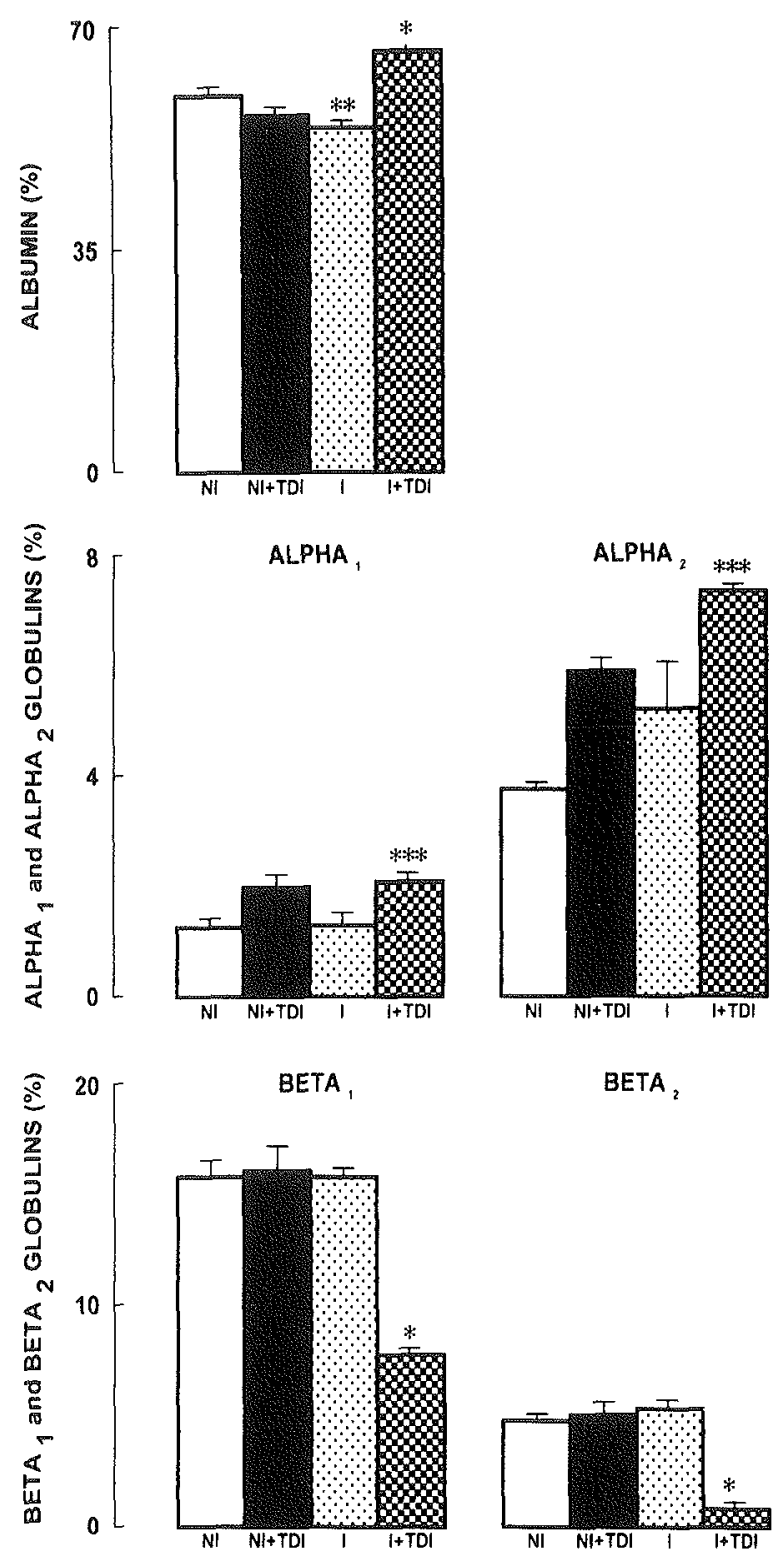

Figure 1. Albumin and globulins (\%) in the 4 groups of guinea pigs studied. Data are expressed as the means and standard errors of the means; $P<0.05$. Albumin (\%) was significanlty increased in TDIimmunized and TDI-challenged animals as compared with nonimmunized unchallenged and TDI-immunized unchallenged animals $\left(^{*}\right)$ and significantly decreased in TDI-immunized unhcallenged animals as compared with nonimmunized unchallenged animals $\left(^{* *}\right)$. Alpha ${ }_{1}$ and alpha ${ }_{2}$ globulins (\%) were significantly increased in TDI-immunized and TDI-challenged animals as compared with nonimmunized unchallenged and TDI-immunized unchallenged animals ${ }^{* * *}$. Beta ${ }_{1}$ and beta $_{2}$ globulins were significantly decreased in TDI-immunized and TDI-challenged animals as compared with nonimmunized unchallenged animals $\left({ }^{*}\right)$. 


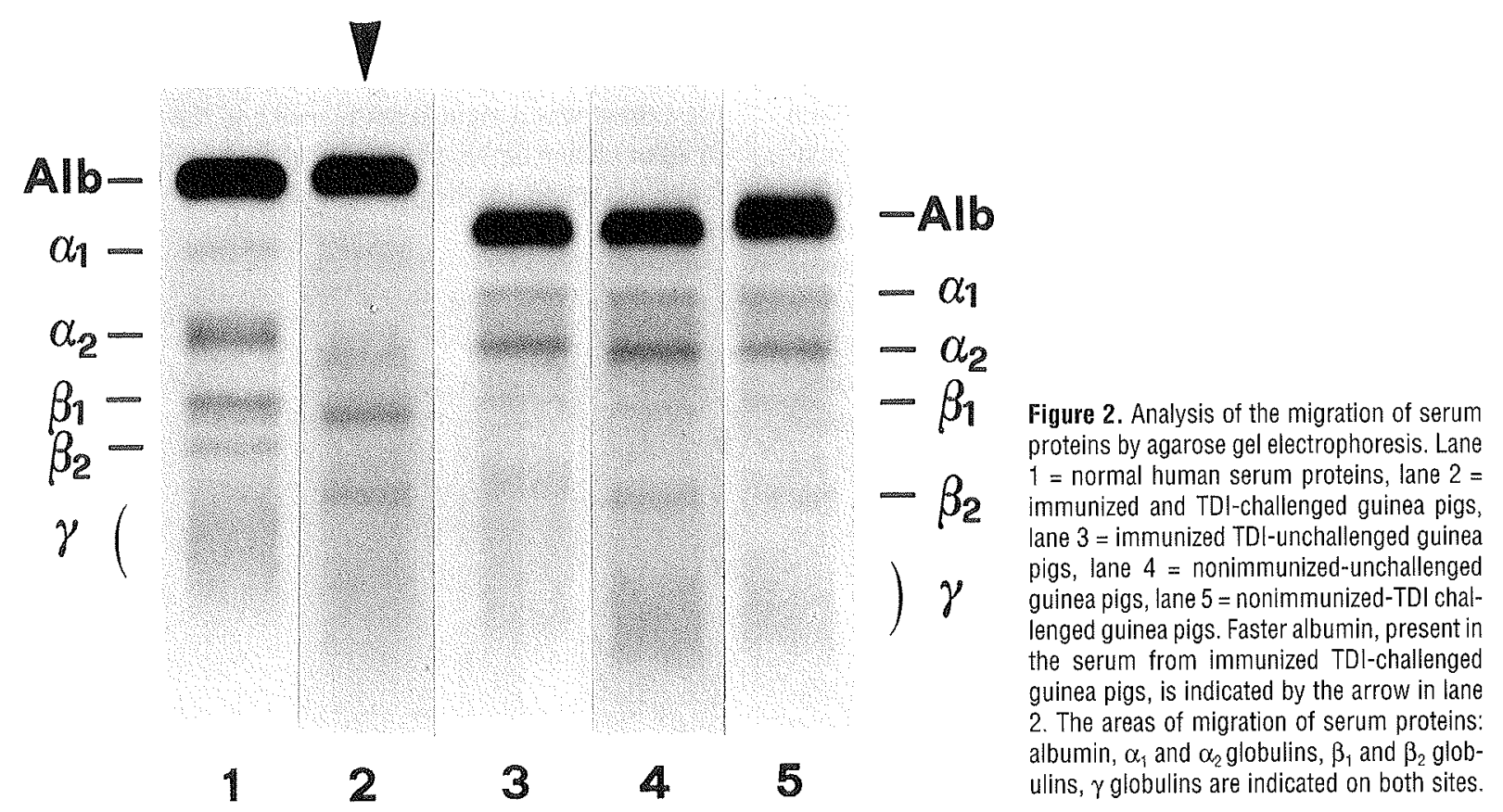

compared with the corresponding values of both the nonimmunized unchallenged and immunized unchallenged guinea pigs (figure 1, see page 155). In the nonimmunized TDI-challenged guinea pigs, there was a small, but

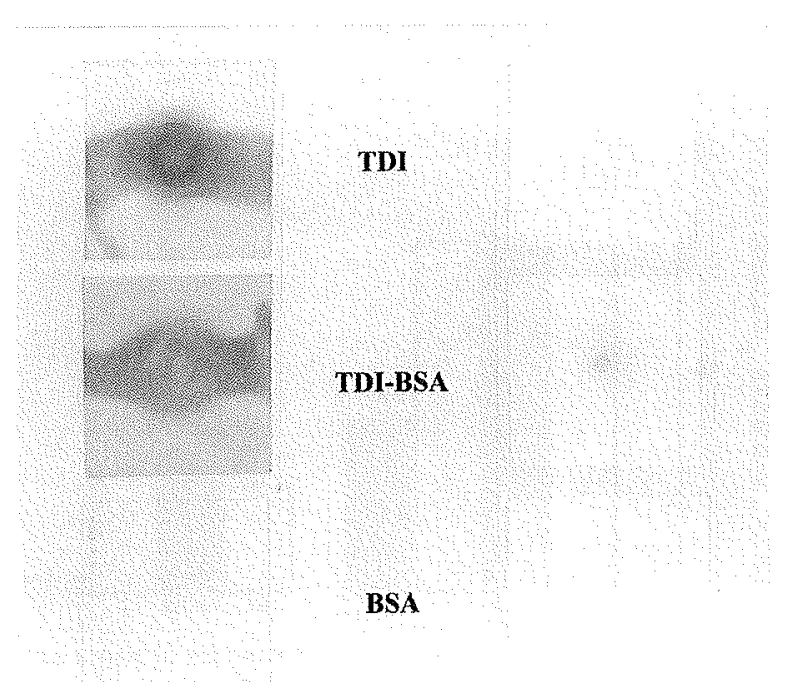

Figure 3. Specificity of guinea-pig-immune serum against toluene diisocyanate (TDI), conjugate of TDI and bovine serum albumin (BSA), and BSA alone under native conditions by dot blot analysis. TDI, TDIBSA conjugate, and BSA alone were absorbed by nitrocellulose dot and then reacted with guinea pig immune serum and secondary antibody anti-guinea pig $\mathrm{lgG}$. In the left lane, it is shown that guinea-pig-immune serum reacted against TDI and TDI-BSA, but not against BSA alone. In the right lane, it is shown (control experiments) that the secondary antibody anti-guinea pig immunoglobulin $G$ did not react with TDI, TDF-BSA conjugate, or BSA alone. not significant increase in the alpha $a_{1}$ and alpha $_{2}$ globulins when they were compared with the TDI-unchallenged guinea pigs. Conversely, the percentage of gamma globulins did not change significantly in the immunized TDI-challenged guinea pigs as compared with the levels of the other 3 groups [16.3 (SE 0.3)\%, 18.5 (SE $0.7) \%, 15.5$ (SE 1.1)\% and 15.2 (SE 1.6)\%, respectively].

We also found that, in the immunized TDI-challenged guinea pigs, albumin ran faster on agarose gel electrophoresis as compared with the albumin of the other 3 groups (higher band on lane 2, figure 2). This finding was confirmed by cellulose acetate electrophoresis.

\section{Imunoglobulin $G$ and $G_{1}$ titers}

Total IgG and $\operatorname{IgG}_{1}$ antibodies specific for TDI were observed only for the immunized guinea pigs. Total IgG antibodies to TDI were found, 1:23.800 (1.90) and $1: 27.950(1.60)$, respectively, in the TDI-challenged and unchallenged animals. The $\operatorname{IgG}_{1}$ titers were $1: 9.060$ (1.38) and 1:8320 (2.75) (titers as GM and GSEM), respectively, in the TDI-challenged and unchallenged animals. There was no significant difference in the $\operatorname{IgG}$ and $\operatorname{IgG}_{1}$ titers between the TDI-challenged and unchallenged animals.

\section{Dot blot, SDS-PAGE and Western blot analysis}

Antibodies obtained against TDI recognized TDI-BSA, a conjugate commonly used to immunize animals in models of TDI-induced asthma. In the dot blot, under native conditions, the antibodies against TDI were able to recognize TDI alone, and TDI-BSA conjugates, but not BSA alone (figures 3 and 4). On SDS-PAGE, when 
TDI-guinea pig serum conjugate was loaded and tested with immune serum anti-TDI, several serum proteins were labeled, mainly proteins with a molecular weight around 116, 66, 59 and 29 kilodaltons (figure 5, lane 1). In the experiments in which the guinea pig immune serum anti-TDI was saturated with guinea pig $\operatorname{IgG}$, only the reaction with the protein of molecular weight 116 kilodaltons persisted (figure 5, lane 2). As a control, when unconjugated guinea pig serum was loaded and tested with immune guinea pig serum against TDI, no reaction appeared (figure 5, lane 3).

\section{Discussion}

This study showed that, in immunized guinea pigs, 6 hours after TDI-challenge, when the airway cell inflammatory infiltrate was maximal, there was also an "acute phase response" characterized by a modification in the concentration of serum proteins. Immunization and challenge with TDI caused an increase in the total serum protein concentration and the albumin and alpha globulin

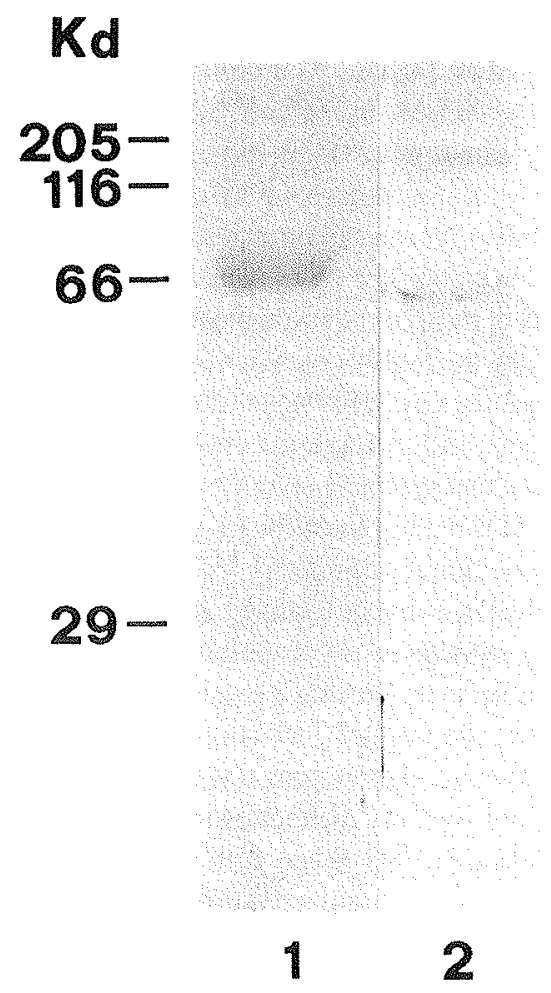

Figure 4. Specificity of guinea-pig-immune serum against TDI-BSA conjugate under denaturated conditions by SDS-PAGE and Western blot analysis. TDI $\left(2 \times 10^{-4} \mathrm{M}\right)$-BSA conjugate (lane 1) and BSA alone (lane 2) were separated by SDS-PAGE and transferred to nitrocellulose. Guinea-pig-immune serum reacted against the TDI-BSA conjugate, but not against BSA alone. Standard molecular weights (in kilodaltons) are shown on the left. (TDI = toluene diisocyanate; $B S A=$ bovine serum albumin; SDS-PAGE = sodiumdodecylsulfate-polyacrylamide gel electrophoresis) concentrations and a decrease in the beta globulins, with no significant modification of the gamma globulins.

Within the spectrum of systemic reactions to inflammation, alterations in metabolism and gene regulation in the liver have been described $(21,22)$. IL-6-type cytokines and IL-1-type cytokines act as primary stimulators of the acute phase plasma proteins (APP) gene-expression, while glucorticoids and growth factors are modulators of cytokine action. The "acute phase response" (APR) has a protective and homeostatic role in the host response. However, it is unknown which events convert the normal acute phase response to chronic inflammation. An increase in the alpha globulins and a decrease in the beta globulins are characteristic of the acutephase inflammatory response, when an injury is

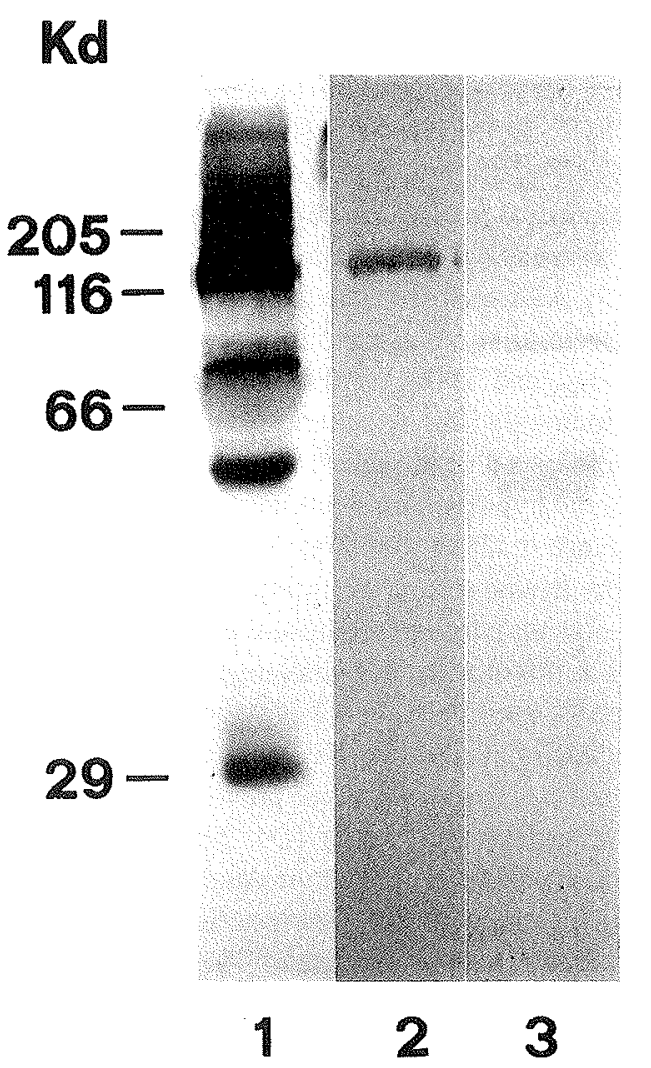

Figure 5. Specificity of guinea-pig-immune serum against TDI-guinea-pig-serum conjugate and normal serum alone under denaturated conditions by SDS-PAGE and Western blot analysis. TDI $\left(2 \times 10^{-4} \mathrm{M}\right)-$ guinea-pig-serum conjugate and normal guinea-pig serum alone were separated by SDS-PAGE, transferred to nitrocellulose, and tested with antibodies against TDI. When the TDI-guinea-pig-serum conjugate was tested with immune serum anti-TDI, several serum proteins were labeled, mainly proteins with molecular weights around 116, 66, 59 and 29 kilodaltons (lane 1). When the guinearpig-immune serum antiTDI was previously saturated with guinea pig immunoglobulin $G$, the reaction with the protein with a molecular weight of 116 kilodaltons was the only one which persisted (lane 2). When unconjugated guinea-pig serum was tested (control experiments), no reaction appeared (lane 3). Standard molecular weights (in kilodaltons) are shown on the left. (TDI= toluene diisocyanate; SDS-PAGE= sodiumdodecylsulfate-polyacrylamide gel electrophoresis) 
localized in one organ. It is possible that the action of TDI on the airways may determine the release of soluble mediators that mobilize the metabolic response of the whole organism (23). In terms of electrophoretic mobility, alpha globulins include alpha ${ }_{1}$-antitrypsin, alpha $2_{2}^{-}$ macroglobulin and haptoglobin, beta globulins include transferrin and complement (fraction C3), and, finally, gamma globulins include immunoglobulins and C-reactive proteins (24). Globulins are almost synthesized in the liver with the exception of immunoglobulins, and it has been found that their concentration changes dramatically within hours of the beginning of injury (25). Extrahepatic synthesis and altered catabolism seem to play a less important role in increasing blood levels of the proteins synthesized in the liver (25). The cells which commonly trigger the cascade of events during the acutephase inflammatory response are tissue alveolar macrophages and blood monocytes (23). Activated cells may release a broad spectrum of mediators, such as interleukin 1 (IL-1), interleukin 6 (IL-6), and tumor necrosis factor (TNF) families, which appear to be important to the induction of the liver synthesis of globulins and also appear to act as "alarm cytokines" both locally and distally (23). Although able to stimulate directly the hepatic synthesis of some acute phase proteins in vitro (26, $27), \mathrm{IL}_{-} 1_{\text {beta }}$ and $\mathrm{TNF}_{\text {alpha }}$ probably control the liver response indirectly (28) by enhancing the production of IL6 in fibroblasts and activating the release of corticosteroids via the hypothalamus-pituitary-adrenal axis. Then, the increase in alpha globulins and the decrease in beta globulins in the serum of immunized TDI-challenged guinea pigs may reflect the inflammatory process in the airways 6 hours after the challenge, and the influx of eosinophils, mast cells, and T lymphocytes may initiate the cascade of mediators. Evidence for a role of IL-1type cytokines comes from our previous studies on subjects with asthma induced by TDI (29). We found a persistent activation of lymphocytes and a chronic expression of proinflammatory cytokines (ie, IL- $1_{\text {beta }}$ and TN$\mathrm{F}_{\text {alpha }}$ ) in the bronchial mucosa of TDI-asthmatics when they were compared with controls. This study has shown that the protein changes occurred only in immunized TDI-challenged animals, but not in immunized unchallenged or nonimmunized TDI-challenged guinea pigs, suggesting that the appearance of changes in serum proteins seems to require both the immunization and challenge with the sensitizing agent (TDI). We do not know whether this response was specific for TDI or not. In fact, other studies have shown that, for example, alpha $a_{2}-$ globulin haptoglobin (Hp) levels increased during exacerbations of asthma (30), such as in ankylosing spondylitis (31) and contact sensitivity (32), a finding suggesting that $\mathrm{Hp}$ levels are more likely to be nonspecific markers of inflammation. We believe that the effect of TDI on serum proteins was mediated by the inflammatory cells recruited and activated in the airways, but we cannot exclude a direct effect of TDI on the synthetic activity of the liver cells, although it seems unlikely. In fact, animal studies have shown that, after vapor challenge to ${ }^{14 C}$ TDI, a detectable amount of radioactivity can also be found in the liver and in the bile, even if in an amount much lower than in the airways (8). We did not measure single proteins electrophoretically. Further studies will be necessary to verify which single protein increases or decreases in relation to the inflammatory action of TDI on the airways. The increase in the concentration of alpha globulins and the decrease in the concentration of beta globulins in the peripheral blood of guinea pigs may reflect the inflammation occurring in the airways at the same time.

In immunized TDI-challenged animals, the amount of albumin increased and albumin ran electrophoretically faster than that from nonimmunized guinea pigs. It is possible that both of these changes are due to the covalent binding of TDI to albumin $(33,34)$. Using dot blot, we found that antibodies recognized both TDI and TDIalbumin conjugates; these results may confirm the ability of TDI to act as a hapten to many other proteins. TDI was also able to bind other serum proteins, in agreement with the findings of other studies with guinea pigs (35). These isocyanate adducts to proteins and peptides have been recently studied. In humans, albumin adducts were present in plasma, whereas, in guinea pigs, albumin adducts were localized in alveolar macrophages, in airway epithelial cells (36), and in bronchoalveolar lavage fluid (BAL) (35), whereas hemoglobin adducts were identified in BAL and in peripheral erythrocytes (37). The mechanism by which the highly reactive diisocyanates are transported across the epithelial layer of the respiratory tract, into the blood, and through the erythrocyte membranes to react with hemoglobin is unknown. In vitro, it has been shown that TDI readily forms bis(S-glutathionyl) adducts under physiological conditions (38). All these studies have demonstrated that isocyanates are readily transferred from serum adducts to nucleophilic sites of proteins on cellular membranes. Further experiments are necessary to investigate the role of TDI adducts in the sensitization and the immunogenic processes.

We did not find any difference in the amount of total gamma globulins, but there was an increase of IgG against TDI in the immunized animals. The presence of specific immunoglobulins against TDI has been demonstrated in subjects sensitized to the chemical $(9,10)$, but the role of these specific antibodies against TDI is still unclear.

In conclusion, the present study of the "acute phase response" in immunized and TDI-challenged guinea pigs demonstrated a significant increase in serum proteins of the acute-phase inflammatory response and TDIinduced modifications of albumin, findings confirming 
the ability of TDI to form adducts with several serum proteins. In this respect, further studies are needed to verify whether the changes in serum proteins are due to any particular protein and whether these changes may be useful in the monitoring of human TDI-induced asthma.

\section{Acknowledgments}

This study was supported by the European Commission within the frame of the Biomedical and Health Research Programme (BMH1, CT 94-1281), by the Ministero dell'Universita' e della Ricerca Scientifica e Tecnologica $(60 \%, 40 \%)$, by the National Research Council, and by Associazione per la Ricerca e la Cura dell'Asma.

We wish to thank Professor Meryl H. Karol for her collaboration in measuring the total IgG and specific antibodies against TDI, G Fulgeri for typing the manuscript, and CA Drace-Valentini for editing the manuscript.

\section{References}

1. Brown WE. The chemistry and biochemistry of isocyanates: an overview. In: Hollinger MA, editor. Current topics in pulmonary pharmacology and toxicology. New York (NY): Elsevier Scientific Publishing Co, 1986:200-25.

2. Ozawa $\mathrm{H}$. Bridging reagent for protein, I: the reaction of diisocyanates with lysine and enzyme protein. J Biochem 1967;62:419-23.

3. Brown WE, Wold F. Alkyl isocyanates as active site specific reagents for serine proteases: identification of the active site serine as the site of reaction. Biochemistry 1973;12:835-51.

4. Dewair M, Baur X, Mauermayer R. Inhibition of acetylcholinesterase by diisocyanate and its spontaneous reactivation. Int Arch Occup Environ Health 1983;52:257-61.

5. Garssen J, Nijkamp DP, Van der Vliet H, Van Loveren H. A role for cellular immunity in the induction of airway hyperresponsiveness induced by small molecular weight compounds. Toxicol Lett 1994;72:151-4.

6. Mapp CE, Saetta M, Maestrelli P, Di Stefano A, Chitano P, Boschetto $P$, et al. Mechanisms and pathology of occupational asthma. Eur Respir J 1994; 7:544—54.

7. Karol MH. Animal models of occupational asthma. Eur Respir J 1994:7:555-68.

8. Kennedy AL, Wilson JR, Stock MF, Alarie Y, Brown WB. Distribution and reactivity of inhaled ${ }^{14} \mathrm{C}$ - labeled toluene disocyanate (TDI) in rats. Arch Toxicol 1994;68:434-43.

9. Butcher BT, O'Neil CE, Reed MA, Salvaggio J. Radioallergosorbent testing of toluene diisocyanate-reactive individuals using p-tolyl isocyanate antigen. J Allergy Clin Immunol 1980;60:213-6.

10. Grammer LC, Harris KE, Malo JL, Cartier A, Patterson R. The use of an immunoassay index for antibodies against isocyanate human protein conjugates and application to human isocyanate disease. J Allergy Clin Immunol 1990;86:94—8.

11. Mapp CE, Saetta M, Maestrelli P, Ciaccia A, Fabbri LM. Low molecular weight pollutants and asthma: pathogenetic mecha- nism and genetic factors [editorial]. Eur Respir J 1994;7:1559-63.

12. Finotto S, Fabbri LM, Rado V, Mapp CE, Maestrelli P. Increase in numbers of CD8 positive lymphocytes and cosinophils in peripheral blood of subjects with late asthmatic reactions induced by toluene diisocyanate. $\mathrm{Br} \mathbf{J}$ Ind Med 1991;48:116-21.

13. Maestrelli P, Calcagni PG, Saetta M, Di Stefano A, Hosselet JJ, Santoanastaso A, et al. Sputum eosinophilia after asthmatic responses induced by isocyanates in sensitized subjects. Clin Exp Allergy 1994;24:29-34.

14. Maestrelli P, Del Prete GF, De Carli M, D'Elios MM, Saetta M, Di Stefano A, et al. CD8 T-cell clones producing interleukin-5 and interferon-gamma in bronchial mucosa of patients with asthma induced by toluene diisocyanate [case report]. Scand J Work Environ Health 1994;20:376-81.

15. Baumann $\mathrm{H}$, Gauldie $\mathrm{J}$. The acute phase response. Immunol Today 1994;15:74-80.

16. Mapp CE, Lapa e Silva JR, Lucchini RE, Chitano P, Rado V Saetta M, et al. Inflammatory events in the blood and airways of guinea pigs immunized to toluene diisocyanate. Am J Respir Crit Care Med 1996;154:201-8.

17. Karol MH, Jin R. Mechanism of immunotoxicity to isocyanates. Chem Res Toxicol 1991;(5):503-9.

18. Lowry OH, Rosebrough NJ, Farr AL, Randall LJ. Protein measurement with the folin phenol reagent. J Biol Chem 1951;193:265-75.

19. Laemmli UK. Cleavage of structural proteins during the assembly of the head of bacteriophage. Nature 1970;227:680 5.

20. Towbin H, Staehlin T, Gordon J. Electrophoretic transfer of proteins from polyacrylamide gels to nitrocellulose sheets: procedure and some applications. Proc Natl Acad Sci (USA) 1979;76:4350-4.

21. Baumann H, Gauldie J. Hepatocyte-stimulating factor, beta 2 interferon, and interleukin- 1 enhance expression of the rata alpha 1 acid glycoprotein gene via a distal upstream regulatory region. Cell Biol Med 1988;8:42-51.

22. Gauldie J, Richards C, Harnish D. Interferon beta $2 / B$ cell stimulatory factor type 2 shares identity with monocyte-derived epatocyte-stimulating factor and regulates the major acute phase protein response in liver cells. Proc Natl Acad Sci USA 1987;84:7251-5.

23. Kushner I, Mackiewicz A. Acute phase proteins as disease markers. Dis Markers 1987;5:1-11.

24. Aguzzi F, Pozzi N, Chiara T. Interpretation of serum protein electrophoresis. Ric Clin Lab 1978;8(1):171.

25. Klaassen CD. Distribution, excretion, and absorption of toxicants. In: Klaassen CO. Amdur MO, Doull J, editors. Toxicology: the basic science of poisons. 3rd ed. New York (NY): Macmillan, 1986:33-63.

26. Ramadori G, Sipe JD, Dinarello CA, Mizel SB, Colten HR Pretranslational modulation of acute phase hepatic protein synthesis by murine recombinant interleukin1 (IL-1) and purified human IL-1. J Exp Med 1985;162:930-2.

27. Perlmutter DH, Dinarello CA, Punsal PI, Colten HR. Cachectin tumor necrosis factor regulates hepatic acute phase gene expression. J Clin Invest 1986;78:1349-52.

28. Van Damme J, Opdenakker G, Simpson RJ, Rubira MR, Cayphas S, Vink A, et al. Identification of the human $26 \mathrm{~K}$ protein (IFN-beta2) or a B-cell hybridoma/plasmacytoma growth factor induced by interleukin-1 and tumor necrosis factor. J Exp Med 1987;165:914-8.

29. Maestrelli P, Di Stefano A, Occari P, Turato G, Milani GF, 
Pivirotto F, et al. Cytokines in the airway mucosa of subjects with asthma induced by toluene diisocyanate. Am J Respir Crit Care Med 1995;151:607-12.

30. Koh YY, Kim W, Park D, Oh JW. A comparison of serum haptoglobin levels between acute exacerbation and clinical remission in asthma. Clin Exp Allergy 1996;26:1202-9.

31. Reynolds TL, Khan MA, van der Linden S, Cleveland RP. Differences in HLA-B27 positive and negative patients with ankylosing spondylitis: study of clinical disease activity and concentrations of serum $\operatorname{IgA}, \mathrm{C}$ reactive protein, and haptoglobin. Ann Rheum Dis 1991;50:154-7.

32. Kimber I, Ward RK, Shepered CI. Acute-phase proteins and the serologic evaluation of experimental contact sensitivity in the mouse. Int Arch Allergy Appl Immunol 1989;89:149_ 55.

33. Lind $P$, Dalene $M$, Lindstrom V, Grubb A, and Skarping G. Albumin adducts in plasma from workers exposed to toluene diisocyanate. Analyst 1997;122:151-4.

34. Kochman S, Lefebvre S, Bernard J, Maujean A, Cazabat A, Lavaud $F$, et al. Toluene diisocyanate-induced conformation- al changes of serum albumin: a study on repeated inhalations in guinea pigs. Toxicol Lett 1990;50:165-71.

35. Jin B, Day BW, Karol MH. Toluene diisocyanate protein adducts in the bronchoalveolar lavage of guinea pigs exposed to vapors of the chemical. Chem Res Toxicol 1993;6:90612.

36. Karol MH, Jin R, Lantz RC. Immunohistochemical detection of toluene diisocyanate (TDI) adducts in pulmonary tissue of guinea pigs following inhalation exposure. Inhalation Toxicol 1987;9:63-83.

37. Day BW, Jin R, Karol MH. Reactions of toluene diisocyanate isomers with guinea pig hemoglobin in vitro and in vivo. Chem Res Toxicol 1996;9:568-73.

38. Day BW, Jin R, Basalyga DM, Kramarik JA, Karol MH. Formation, solvolysis and transcarbamoylation reactions of bis (S-glutathionyl) adducts of 2,4-and 2,6-diisocyanatotoluene. Chem Res Toxicol 1997;10:424-31.

Received for publication: 18 March 1999 